\title{
Measurement of the Industrial Collaboration of the Diversified Coal Industry: China Coal Energy Company as an Example
}

\author{
Chong-Mao Li, Tao Cui, Rui Nie, and Xin-Yu Yan \\ School of Management, China University of Mining and Technology, Xuzhou 221116, China \\ Correspondence should be addressed to Chong-Mao Li; lcm@cumt.edu.cn and Rui Nie; nierui_cumt@outlook.com
}

Received 7 September 2016; Accepted 15 January 2017; Published 15 February 2017

Academic Editor: Anna M. Gil-Lafuente

Copyright (C) 2017 Chong-Mao Li et al. This is an open access article distributed under the Creative Commons Attribution License, which permits unrestricted use, distribution, and reproduction in any medium, provided the original work is properly cited.

\begin{abstract}
With the diversified development of coal enterprises in China, the industries related to coal, including coal chemical, electric power, transportation, and building materials, have witnessed rapid development. There is a collaboration relation between the coal industries and most of the aforementioned industries. Based on the synergy theory and the theory of industrial cooperation, the collaboration among coal industries is assessed in this research. Examining China Coal Energy Company as an example, this research divides the compound enterprise system into subsystems such as coal-electric, coal-chemical, and coal-equipment. Next, collaboration indices, including market, scale, and management, are created for each subsystem. Then, the overall collaboration degree of the China Coal Energy Company since it was listed was calculated by standardizing data and estimating the order degree of order parameters and subsystems. Thus, a model measuring the industrial collaboration degree of coal enterprises was established to quantitatively reflect the collaboration degree between various industries. At the same time, the factors influencing the collaboration effect between various industries were analyzed so as to improve this effect, which then can provide a decision basis for enterprises.
\end{abstract}

\section{Introduction}

Since 2012, coal enterprises in China have witnessed great fluctuation in terms of their management performance due to influences of the macroeconomy. At the same time, affected by surplus production, the impact of imported coal, increased environmental protection pressure, and weakened downstream demands, China's coal enterprises have suffered extensive losses $[1,2]$. The excessive dependence of the coal enterprises on the leading coal industries has led to the further development of such enterprises being restricted by the limitation of coal resources and the fluctuation of coal markets.

Under this new circumstance, large-scale coal enterprises in China have adjusted their development according to their own development state. As a result, a development pattern dominated by coal has formed accompanied by the development of other products. This has enhanced the economic benefit and comprehensive development capacities of other industries to some extent. According to a survey of the industries involved in the main coal enterprises in China, along with the diversification of coal enterprises, the industries related to coal industries, including coal chemical, electric power, transportation, and building materials industries, have experienced rapid development. At the same time, coal industries present a collaborative relation with most of the aforementioned industries.

Based on the theory of industrial collaboration, the collaboration of coal industries is examined in this research. The established model for measuring the industrial collaboration degree of coal enterprises can quantitatively reflect the collaboration degree between various industries. In addition, the factors influencing the collaboration effect between various industries are analyzed, so as to enhance the collaboration effect, which can then provide a decision basis for enterprises.

\section{Literature Review}

Ansoff $[3,4]$ described the combined effect available to a diversified firm as synergy. He suggested that synergy can produce a return on combined resources that is greater than the sum of the individual parts. According to Haken [5, 6], synergy means working together. As transferred from the microscopic to the macroscopic level, synergy describes 
a generality where various systems with special properties transform from a disordered to an ordered state.

$\mathrm{Hu}$ [7] indicates that industrial collaboration refers to the high degree of consistency or harmoniousness from mutual interactions and cooperation in the production, marketing, purchase, management, and technology of the enterprises within the cluster.

Theoretical studies regarding industrial collaboration were first performed on industrial collaboration between regions. For example, such research studied the influences of the driving effects of industrial collaboration, collaboration of industrial clusters and technology industries, and industry transfer through the collaborative development of industries. Generally speaking, many scholars held that realizing the industrial collaboration effect by improving the degree of industrial collaboration would be beneficial in enhancing the benefits to the enterprises [8-11]. The goals of industrial collaboration include acquiring collaborative benefits, reducing production costs, enhancing production efficiency, and improving levels of specialization and scale of enterprises.

While describing the behaviors near the critical point, Haken $[5,6]$ introduced order parameters. As representative of collective collaborative behavior affecting the transformation of various system elements from one phase to another, order parameters refer to the change newly appearing during the evolution process of a system and can indicate the parameters formed by new structures. Therefore, order parameters are considered the key factors leading to change in the degree of industrial collaboration in this research, and their existence and change result in the variation of the collaboration degree.

With the proposal of the concept of collaboration and its deepening investigation, models measuring the degree of collaboration have been established and improved on by scholars [12-16]. Although these models target different problems, they all lay an academic foundation for the research here. The frequently used method for measuring the industrial collaboration degree is the efficacy function method of order parameters. However, theoretical and empirical research still lacks a common understanding of industrial collaboration degree measurement in the coal industry.

When it comes to measuring the industrial collaboration degree for coal enterprises, first, the enterprises are divided into several industrial subsystems. Then, the order parameters and indices are established for each industry. Examining China Coal Energy Company as an example, this research obtains the specific parameters of each index through its investigation. Meanwhile, the expert weighting method is employed to weigh each subsystem and the order parameters of different hierarchies. Subsequently, the degree of industrial collaboration among coal enterprises is measured by establishing a measurement system from top to bottom.

\section{The Establishment of the Model for Measuring the Collaboration Degree}

3.1. The Efficacy Function Method of Order Parameters [1618]. Large-scale coal enterprises are comprised of several internally connected industrial subsystems, the integration of which constitutes a compound system with a higher hierarchy, namely, the multi-industry compound system of coal enterprises. The whole system is labeled as $s=\left(s_{1}, s_{2}, \ldots, s_{n}\right)$, where $s_{n}$ represents the $n_{\text {th }}$ industrial subsystem. During the evolution process of the system, the order parameter is represented by $g_{j}=\left(g_{j 1}, g_{j 2}, \ldots, g_{j n}\right)$, where $n \geq 1, S_{j}(j \in$ $[1, k]) \alpha_{j i} \leq g_{j i} \leq \beta_{j i}$, and $i \in[1, n]$, . Here, $\alpha_{j i}$ and $\beta_{j i}$ represent the upper and lower limits of the order parameter, respectively. The value of the order parameter is related to the numerical values of different indices. As a general rule, the order degree of a system is divided into two categories: in the first category, the order degree is positively correlated with the value of $g_{j 1}, g_{j 2}, \ldots, g_{j k_{1}}$; in the second one, the order degree is in negative correlation with the value of $g_{j k_{1}+1}, \ldots, g_{j n}$. Based on the aforementioned analysis, formula (1) is defined as the order degree of the component $g_{j i}$ of the order parameter for the industrial subsystem $s_{j}$ :

$$
u_{j}\left(g_{j i}\right)= \begin{cases}\frac{g_{j i}-\alpha_{j i}}{\beta_{j i}-\alpha_{j i}}, & i \in\left[1, k_{1}\right], \\ \frac{\beta_{j i}-g_{j i}}{\beta_{j i}-\alpha_{j i}}, & i \in\left[k_{1}+1, n\right] .\end{cases}
$$

According to the definition mentioned above, we obtain $u_{j}\left(g_{j i}\right) \in[0,1]$, whose value reflects the contribution degree of $g_{j i}$ to the order degree of the system: the greater the value of $u_{j}\left(g_{j i}\right)$, the greater the contribution degree of $g_{j i}$. Generally speaking, the total contribution of the order parameter $g_{j}$ can be obtained through the integration of $u_{j}\left(g_{j i}\right)$.

Integration methods can be utilized to calculate the total contribution of the index variables to the coordination degree of the subsystems. The commonly used integration methods include the geometric mean, as seen in formula (2), and the linear weighted summation, as demonstrated in formula (3).

$$
\begin{aligned}
& u_{j}\left(g_{j}\right)=\sqrt[n]{\prod_{i=1}^{n} u_{j}\left(g_{j i}\right)}, \\
& u_{j}\left(g_{j}\right)=\sum_{i=1}^{n} \mu_{i} u_{j}\left(g_{j i}\right), \quad \mu_{i} \geq 0, \sum_{i=1}^{n} \mu_{i}=1 .
\end{aligned}
$$

The aforementioned $u_{j}\left(g_{j}\right)$ is considered the order degree of the order parameter $g_{j}$ of the subsystems. It can be seen that $u_{j}\left(g_{j}\right) \in[0,1]$, the value of which reflects the contribution degree of the order parameter $g_{j}$ to the order degree of the industrial subsystem $s_{j}$. The value of $u_{j}\left(g_{j}\right)$ is positively correlated with the order degree of the industrial subsystem $s_{j}$. That is, the order degree of this subsystem increases with the value of $u_{j}\left(g_{j}\right)$ and vice versa.

After calculating the order degrees of each subsystem, the overall collaboration degree $(D)$ of the enterprise requires calculation. In order to calculate the collaboration degree of the enterprise in the current year, the linear weighted summation is performed on the weights of each subsystem, as follows:

$$
D=\sum_{j=1}^{n} \lambda_{j} d_{j}
$$


where $\lambda_{j}$ represents the contribution degree of each subsystem to the compound system, namely, the weight of each subsystem, while $d_{j}$ represents the order degree of subsystem and $\lambda_{j} \geq 0, \sum_{j=1}^{n} \lambda_{j}=1$. The greater the value of $D$, the better the overall collaboration degree of the enterprise and the more sufficient utilization of the industrial collaboration effect for each enterprise.

In order to better understand the measure model of collaboration degree, descriptions are given to some items requiring further definition in the model.

(1) While calculating the order degree of order parameters and the overall collaboration degree of enterprises, the weight of each factor needs to be set according to its importance degree. In doing so, the overall contribution degree of each factor to the enterprise is expected to be differentiated since each factor has a different degree of influence on the overall collaboration degree of the enterprise. Therefore, setting weights for indices according to their influence can ensure the accuracy of calculations.

(2) The order degrees of each order parameter and subsystem need to be calculated while calculating the overall collaboration degree of the enterprise. In physics, order degree represents the order degree of the distribution of the various particles contained in a crystal structure in similar structures. However, as applied in the management field, order degree is considered a factor characterizing the collaboration degree of the enterprise. It can be seen from formula (4) that the overall collaboration degree of a system is composed of the order degrees of each subsystem. The collaboration degree between industry sectors can be obtained by analyzing the order degree of the subsystems: the greater the order degree of a subsystem, the greater the collaboration degree between industry sectors. This also suggests that the subsystem is expected to develop into a more ordered direction.

\subsection{The Selection of Order Parameters}

3.2.1. The Principles for Selecting Order Parameters. The principles for selecting order parameters include scientificity, comprehensiveness, accessibility, and the combination of qualitative and quantitative analysis.

3.2.2. Order Parameters. Based on the purpose of this research, the order parameters such as scale, market, and management collaboration are comprehensively considered to favorably analyze the collaborative relationship between industries. Meanwhile, certain indices are selected from the aforementioned order parameters as important references to measure the collaboration degree.

(1) Scale Consistency. Scale consistency refers to the coordination degree of the scale of the industries or the amount of the products of enterprises. It mainly includes the agglomeration effect, the matching degree of capacity, the joint risk resistant ability, and the effect of enterprise cost reductions.
(2) Market Cooperation. Market cooperation indicates that the competitiveness of several industries is enhanced after cooperating with each other, leading to higher performance in the cooperative industries than the sum of the independent industries. The increased performance is mainly induced by saving costs, improving income, and saving capital expenditures. Hereafter, cost savings include the saving of taxes and input materials. Income improvement means an increase in the additional value of the products after industrial cooperation to achieve a greater benefit for the enterprises. The saving of capital expenditures is determined by the type and the degree of repetition of the capital accounts of an enterprise, which is hard to realize.

(3) Management Collaboration. This mainly refers to a change in the efficiency of management activities caused by industrial cooperation and the benefit brought about by improved efficiency. The most active factor-human resources-is involved in this order parameter. This order parameter is mainly influenced by two factors including organizational experience and knowledge capital. Organizational experience refers to improving the skill and ability of the staff through shared learning experiences within enterprises. As for organizational capital, this refers to particular knowledge assets that an enterprise has, mainly assets such as culture, core competencies, specialized staff, and proprietary information.

3.3. The Establishment of the Index System of the Order Parameters for Industries. The index of order parameters refers to the factors that can reflect the characteristics of the selected order parameters. To comprehensively reflect the industrial collaboration, the scale consistency, market cooperation, and management collaboration are applied as the order parameters in this research. Subsequently, based on a survey of coal enterprises, preliminary indices of order parameters are established according to the characteristics of each subsystem. Next, consulting experts modified and improved the index system of the order parameters. In this way, the index system of the order parameters is created to establish the model of the degree of industrial collaboration for coal enterprises, as shown in Table 1.

Table 1 shows three kinds of collaborative factors containing both qualitative and quantitative indices of order parameters. For the convenience of data statistics, the calculation formulas of the aforementioned quantitative indices are given in Table 2.

Apart from the quantitative indices illustrated in Table 2, many qualitative indices are also involved in the selection of the indices of order parameters, which cannot be assigned using existing data. In order to ensure the consistency of the qualitative indices, a five-grade marking system is adopted in the research to divide the value of the indices into six grades ranging from 0 to 5 . The six grades represent the six hierarchies of the indices of order parameters. Hereafter, 0 and 5 indicate the worst and best conditions, respectively, that the order parameters of an industry can achieve under extreme conditions. 
TABLE 1: The indices of order parameters.

\begin{tabular}{|c|c|c|c|}
\hline System & Subsystem & Order parameter & The indices of order parameters \\
\hline \multirow{28}{*}{$\begin{array}{l}\text { The overall } \\
\text { collaboration degree } \\
\text { of coal enterprises }\end{array}$} & \multirow{9}{*}{$\begin{array}{l}\text { Coal-electric } \\
\text { subsystem }\end{array}$} & \multirow{4}{*}{ Scale consistency } & $\begin{array}{l}\text { The proportion of coal consumption in electric power industries } \\
\text { (self-produced coals) }\end{array}$ \\
\hline & & & $\begin{array}{l}\text { The proportion of electric power consumption in coal industries } \\
\text { (self-produced electric power) }\end{array}$ \\
\hline & & & The matching degree of the development scale of coal-electric industries \\
\hline & & & The joint risk resistant ability of coal-electric industries \\
\hline & & \multirow{3}{*}{$\begin{array}{l}\text { Management } \\
\text { collaboration }\end{array}$} & The cultural similarity of coal-electric industries \\
\hline & & & The shared degree of the staff in coal-electric industries \\
\hline & & & The market influence of enterprises \\
\hline & & \multirow[t]{2}{*}{ Market cooperation } & The cost saved in the internal transactions of coal-electric industries \\
\hline & & & The similarity of the marketing mode of coal-electric industries \\
\hline & \multirow{8}{*}{$\begin{array}{c}\text { Coal- } \\
\text { chemical } \\
\text { subsystem }\end{array}$} & \multirow{3}{*}{ Scale consistency } & $\begin{array}{l}\text { The proportion of coal consumption in chemical industries (self-produced } \\
\text { coals) }\end{array}$ \\
\hline & & & The matching degree of the development scale of coal-electric industries \\
\hline & & & The joint risk resistant ability of coal-chemical industries \\
\hline & & \multirow{3}{*}{$\begin{array}{l}\text { Management } \\
\text { collaboration }\end{array}$} & The cultural similarity of coal-chemical industries \\
\hline & & & The shared degree of the staff of coal-chemical industries \\
\hline & & & The degree of market identification of the chemical products of enterprises \\
\hline & & \multirow{3}{*}{ Market cooperation } & The similarity of the marketing mode of coal-chemical industries \\
\hline & & & The cost saved by the use of the self-produced coals (self-produced coals) \\
\hline & \multirow{11}{*}{$\begin{array}{l}\text { Coal- } \\
\text { equipment } \\
\text { subsystem }\end{array}$} & & The market influence of enterprises \\
\hline & & \multirow{4}{*}{ Scale consistency } & The proportion of coal utilized in equipment industries (self-produced coals) \\
\hline & & & $\begin{array}{l}\text { The proportion of the value of the equipment used in coal industries } \\
\text { (self-produced equipment) }\end{array}$ \\
\hline & & & The matching degree of the development scale of coal-equipment industries \\
\hline & & & The joint risk resistant ability of coal-equipment industries \\
\hline & & \multirow{3}{*}{$\begin{array}{l}\text { Management } \\
\text { collaboration }\end{array}$} & The cultural similarity of coal-equipment industries \\
\hline & & & The shared degree of the staff of coal-equipment industries \\
\hline & & & $\begin{array}{l}\text { The degree of the market identification of the equipment produced by } \\
\text { industries }\end{array}$ \\
\hline & & \multirow[t]{3}{*}{ Market cooperation } & The cost saved in the internal transactions of coal-equipment industries \\
\hline & & & The similarity of the marketing mode of coal-equipment industries \\
\hline & & & The market influence of enterprises \\
\hline
\end{tabular}

\section{The Measurement of \\ the Industrial Collaboration Degree of Coal Enterprises: Examining China Coal Energy Company as an Example}

An appropriate statistical data table is established based on the index system of order parameters shown in Table 1. At the same time, the data regarding the indices related to China Coal Energy Company are obtained through an investigation of this enterprise. The main industries China Coal Energy Company is involved in include coal, electric power, chemical, and equipment manufacturing. Therefore, these industries are divided into three subsystems, namely, coalelectric, coal-chemical, and coal-equipment subsystems, according to the model of industrial collaboration.
4.1. The Determination of Order Parameters and the Weights of Their Indices. After obtaining the calculation formulas of order parameters, the analytic hierarchy process (AHP) is utilized to determine the weights of the indices contained in the index system [19-21]. After the relative importance of the indices is evaluated by experts, the relative weights of each order parameter and its index are calculated. To modify and improve the index system of the order parameters, we invited and selected seven experts familiar with large-scale coal enterprise management strategy in China, including two financial department supervisors in coal enterprises, and five experts from research institutions and universities in relevant fields. Table 3 illustrates the distribution of the weights.

4.2. The Measurement of the Industrial Collaboration. According to the introduction on the methods for measuring 
TABLE 2: The calculation formulas of the quantitative indices.

\begin{tabular}{|c|c|}
\hline $\begin{array}{l}\text { Serial } \\
\text { number }\end{array}$ & alculation formula \\
\hline 1 & The proportion of coal consumption = coal consumption of industries/coal production \\
\hline 2 & $\begin{array}{l}\text { The proportion of the electric power consumption of coal industries = electric power consumption of coal industries/the electric } \\
\text { power generated by electric power industries }\end{array}$ \\
\hline 3 & $\begin{array}{l}\text { The cost saved in the internal transactions of coal-electric industries }=\text { the price difference of electric power in the internal and } \\
\text { external transactions of enterprises } \times \text { power consumption of coal industries }+ \text { the price difference of coal in the internal and } \\
\text { external transactions of enterprises } \times \text { coal consumption of electric power industries }\end{array}$ \\
\hline 4 & $\begin{array}{l}\text { The cost saved through the use of self-produced coal }=\text { the price difference of coal in internal and external transactions } \times \text { coal } \\
\text { consumption of chemical industries }\end{array}$ \\
\hline 5 & $\begin{array}{l}\text { The proportion of the value of the building materials utilized in coal industries = the value of the building materials used in coal } \\
\text { industries/the total output value of the building material industries }\end{array}$ \\
\hline 6 & $\begin{array}{l}\text { The cost saved in the internal transactions of coal-building materials industries }=\text { the price difference of coal in the internal and } \\
\text { external transactions of enterprises } \times \text { coal consumption of building material industries }+ \text { the price difference of building } \\
\text { materials in the internal and external transactions of enterprises } \times \text { the amount of the building materials utilized in coal industries }\end{array}$ \\
\hline 7 & The proportion of the self-transported coals $=$ the amount of self-transported coal/the total transport volume of enterprises \\
\hline 8 & $\begin{array}{l}\text { The cost saved in the internal transactions of coal-transportation industries }=\text { the price difference of coal in the internal and } \\
\text { external transactions of enterprises } \times \text { coal consumption of transportation industries }+ \text { the price difference of the transported } \\
\text { coal per ton in the internal and external transactions of enterprises } \times \text { the transport volume of coal industries }\end{array}$ \\
\hline 9 & $\begin{array}{l}\text { The proportion of the value of the steel utilized in coal industries = the value of the steel utilized in coal industries/the total } \\
\text { output value of steel industries }\end{array}$ \\
\hline 10 & $\begin{array}{l}\text { The cost saved in the internal transactions of coal-steel industries }=\text { the price difference of coal in the internal and external } \\
\text { transactions of enterprises } \times \text { coal consumption of steel industries }+ \text { the price difference of steel products in the internal and } \\
\text { external transactions of enterprises } \times \text { steel consumption of coal industries }\end{array}$ \\
\hline 11 & $\begin{array}{l}\text { The proportion of the value of the equipment utilized in coal industries = the value of the equipment utilized in coal } \\
\text { industries/the total output value of equipment manufacturing industries }\end{array}$ \\
\hline 12 & $\begin{array}{l}\text { The cost saved in the internal transactions of coal-equipment industries }=\text { the price difference of coal in the internal and external } \\
\text { transactions of enterprises } \times \text { coal consumption of equipment industries }+ \text { the price difference of equipment products in the } \\
\text { internal and external transactions of enterprises } \times \text { the amount of the equipment utilized in coal industries }\end{array}$ \\
\hline
\end{tabular}

the industrial collaboration degree, the process to measure the overall collaboration degree of the enterprise can be obtained. This includes data standardization, the calculation of the order degrees of order parameters and subsystems, and the measurement of the overall collaboration degree of the enterprise. The process for measuring the industrial collaboration degree of China Coal Energy Company is described specifically as follows.

4.2.1. Data Standardization. First, data are standardized (namely, the nondimensional process) and then calculated according to formula (1).

4.2.2. The Calculation of the Order Degree of Order Parameters for Each Subsystem. According to the size of each index weight shown in Table 3 and formula (3), the order degree of the order parameters are calculated for each subsystem, as shown in Table 4.

\subsubsection{The Calculation of the Order Degrees of Each Subsystem.} After calculating the order degrees of the order parameters for each subsystem, a similar method can be utilized to calculate the order degree of each subsystem. That is, the order degrees of the coal-electric, coal-chemical, and coal-equipment subsystems are calculated according to the weights of the order parameters and formula (3), as seen in Table 5.
4.2.4. The Calculation of the Industrial Collaboration Degree. While calculating the order degree of each subsystem, the variation trends of the order degree can be discovered. In order to describe the development of the overall collaboration degree of the enterprise, the overall collaboration degree needs to be calculated. Formula (4) is utilized to calculate the industrial collaboration degree of China Coal Energy Company in the time period of 2007 to 2014, as demonstrated in Table 6.

\section{Result Analyses}

The variation trend of the collaboration degree of China Coal Energy Company and its subsystems, including coal-electric, coal-chemical, and coal-equipment industries, in the period of 2007 to 2014, is shown according to the above calculated industrial collaboration degrees. The trend is utilized to visually analyze the variation in the collaboration degree of each subsystem and the overall collaboration degree of this enterprise.

Figure 1 displays that although the industrial collaboration degree fluctuates up and down, it shows little variation on the whole, along with a declining tendency. From analyzing the annual reports of the enterprise, we found that the development of the primary businesses of the enterprise began to slow after experiencing a "Golden Age" for coal. Meanwhile, 
TABLE 3: The weights of the order parameters and their indices.

\begin{tabular}{|c|c|c|c|c|}
\hline Subsystem & $\begin{array}{l}\text { Order } \\
\text { parameter }\end{array}$ & $\begin{array}{c}\text { The weight of } \\
\text { the order } \\
\text { parameter }\end{array}$ & The indices of order parameters & Index weight \\
\hline \multirow{9}{*}{$\begin{array}{l}\text { Coal-electric } \\
\text { subsystem }\end{array}$} & \multirow{4}{*}{$\begin{array}{l}\text { Scale } \\
\text { consistency }\end{array}$} & \multirow{4}{*}{0.38} & $\begin{array}{l}\text { The proportion of coal consumption in electric power industries } \\
\text { (self-produced coals) }\end{array}$ & 0.32 \\
\hline & & & $\begin{array}{l}\text { The proportion of electric power consumption in coal industries } \\
\text { (self-produced electric power) }\end{array}$ & 0.15 \\
\hline & & & The matching degree of the development scale of coal-electric industries & 0.30 \\
\hline & & & The joint risk resistant ability of coal-electric industries & 0.23 \\
\hline & \multirow{2}{*}{$\begin{array}{l}\text { Management } \\
\text { collaboration }\end{array}$} & \multirow{2}{*}{0.26} & The cultural similarity of coal-electric industries & 0.50 \\
\hline & & & The shared degree of the staff in coal-electric industries & 0.50 \\
\hline & \multirow{3}{*}{$\begin{array}{l}\text { Market } \\
\text { cooperation }\end{array}$} & \multirow{3}{*}{0.36} & The market influence of enterprises & 0.20 \\
\hline & & & The cost saved in the internal transactions of coal-electric industries & 0.52 \\
\hline & & & The similarity of the marketing mode of coal-electric industries & 0.28 \\
\hline \multirow{9}{*}{$\begin{array}{l}\text { Coal-chemical } \\
\text { subsystem }\end{array}$} & \multirow{3}{*}{$\begin{array}{l}\text { Scale } \\
\text { consistency }\end{array}$} & \multirow{3}{*}{0.38} & $\begin{array}{l}\text { The proportion of coal consumption in chemical industries (self-produced } \\
\text { coals) }\end{array}$ & 0.42 \\
\hline & & & The matching degree of the development scale of coal-electric industries & 0.32 \\
\hline & & & The joint risk resistant ability of coal-chemical industries & 0.26 \\
\hline & \multirow{2}{*}{$\begin{array}{l}\text { Management } \\
\text { collaboration }\end{array}$} & \multirow{2}{*}{0.26} & The cultural similarity of coal-chemical industries & 0.50 \\
\hline & & & The shared degree of the staff of coal-chemical industries & 0.50 \\
\hline & \multirow{4}{*}{$\begin{array}{l}\text { Market } \\
\text { cooperation }\end{array}$} & \multirow{4}{*}{0.36} & The degree of market identification of the chemical products of enterprises & 0.11 \\
\hline & & & The similarity of the marketing mode of coal-chemical industries & 0.31 \\
\hline & & & The cost saved by the use of the self-produced coals (self-produced coals) & 0.46 \\
\hline & & & The market influence of enterprises & 0.12 \\
\hline \multirow{10}{*}{$\begin{array}{l}\text { Coal-equipment } \\
\text { subsystem }\end{array}$} & \multirow{4}{*}{$\begin{array}{l}\text { Scale } \\
\text { consistency }\end{array}$} & \multirow{4}{*}{0.38} & $\begin{array}{l}\text { The proportion of coal utilized in equipment industries (self-produced } \\
\text { coals) }\end{array}$ & 0.26 \\
\hline & & & $\begin{array}{l}\text { The proportion of the value of the equipment used in coal industries } \\
\text { (self-produced equipment) }\end{array}$ & 0.35 \\
\hline & & & The matching degree of the development scale of coal-equipment industries & 0.32 \\
\hline & & & The joint risk resistant ability of coal-equipment industries & 0.07 \\
\hline & \multirow{2}{*}{$\begin{array}{l}\text { Management } \\
\text { collaboration }\end{array}$} & \multirow{2}{*}{0.26} & The cultural similarity of coal-equipment industries & 0.50 \\
\hline & & & The shared degree of the staff of coal-equipment industries & 0.50 \\
\hline & \multirow{4}{*}{$\begin{array}{l}\text { Market } \\
\text { cooperation }\end{array}$} & \multirow{4}{*}{0.36} & $\begin{array}{l}\text { The degree of the market identification of the equipment produced by } \\
\text { industries }\end{array}$ & 0.09 \\
\hline & & & The cost saved in the internal transactions of coal-equipment industries & 0.45 \\
\hline & & & The similarity of the marketing mode of coal-equipment industries & 0.26 \\
\hline & & & The market influence of enterprises & 0.20 \\
\hline
\end{tabular}

TABLE 4: The order degree of the order parameters for each subsystem.

\begin{tabular}{lccccccccccc}
\hline Subsystem & Order parameter & Weight & 2007 & 2008 & 2009 & 2010 & 2011 & 2012 & 2013 & 2014 \\
\hline \multirow{3}{*}{ Coal-electric system } & Scale consistency & 0.38 & 0.6328 & 0.486 & 0.3184 & 0.6111 & 0.4434 & 0.3353 & 0.1706 & 0.4752 \\
& Management collaboration & 0.26 & 0.2 & 0.2 & 0.2 & 0.3 & 0.2 & 0.2 & 0.3 & 0.3 \\
& Market cooperation & 0.36 & 0.216 & 0.4670 & 0.3567 & 0.6505 & 0.736 & 0.6148 & 0.3726 & 0.4234 \\
\hline \multirow{4}{*}{ Coal-chemical subsystem } & Scale consistency & 0.38 & 0.652 & 0.6074 & 0.4625 & 0.2535 & 0.2349 & 0.1271 & 0.116 & 0.22 \\
& Management collaboration & 0.26 & 0.3 & 0.2 & 0.2 & 0.2 & 0.2 & 0.2 & 0.4 & 0.3 \\
& Market cooperation & 0.36 & 0.18 & 0.4814 & 0.3711 & 0.4706 & 0.64 & 0.4582 & 0.5043 & 0.4365 \\
\hline \multirow{3}{*}{ Coal-equipment subsystem } & Scale consistency & 0.38 & 0.6382 & 0.662 & 0.6473 & 0.3591 & 0.5195 & 0.3464 & 0.1704 & 0.17 \\
& Management collaboration & 0.26 & 0.6 & 0.7 & 0.6 & 0.6 & 0.6 & 0.6 & 0.7 & 0.6 \\
& Market cooperation & 0.36 & 0.458 & 0.44 & 0.458 & 0.388 & 0.388 & 0.388 & 0.348 & 0.348 \\
\hline
\end{tabular}


TABLE 5: The order degree of each subsystem.

\begin{tabular}{lcccccccc}
\hline Subsystem & 2007 & 2008 & 2009 & 2010 & 2011 & 2012 & 2013 & 2014 \\
\hline Coal-electric subsystem & 0.3702 & 0.4048 & 0.3014 & 0.5444 & 0.4854 & 0.4008 & 0.2510 & 0.411 \\
Coal-chemical subsystem & 0.3905 & 0.4561 & 0.3614 & 0.3177 & 0.3717 & 0.2653 & 0.3296 & 0.3188 \\
Coal-equipment subsystem & 0.5634 & 0.5920 & 0.5669 & 0.4321 & 0.4931 & 0.4273 & 0.3720 & 0.3459 \\
\hline
\end{tabular}

TABLE 6: The industrial collaboration degree by year.

\begin{tabular}{lcccccccc}
\hline & 2007 & 2008 & 2009 & 2010 & 2011 & 2012 & 2013 & 2014 \\
\hline The overall collaboration degree of the enterprise & 0.4413 & 0.4843 & 0.4099 & 0.4314 & 0.4501 & 0.3645 & 0.3175 & 0.3586 \\
\hline
\end{tabular}

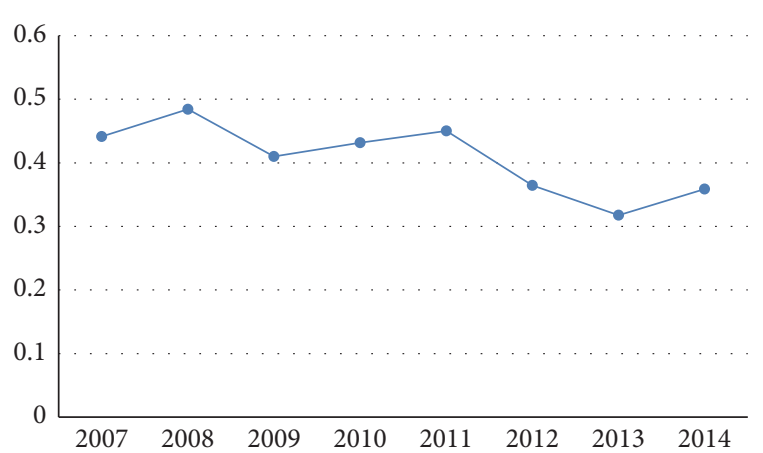

FIGURE 1: The variation trend of the collaboration degree of China Coal Energy Company in the period of 2007 to 2014.

affected by external factors such as the market, both the costs saved in the internal transactions between industries and the degree of interavailability among the products of different industries declined. This resulted in a reduced level of collaborative development of each subsystem, which has a great influence on the development of the enterprise and its industries.

In 2008, the order degree of each subsystem was well developed, and the collaborative relationships between various industries and the coal industry were strong. As a result, the overall collaboration degree of the enterprise increased. In contrast, in 2009, all subsystems exhibited unsatisfactory collaboration degrees with a declining tendency, leading to the obviously reduced overall collaboration degree of the enterprise. During the period from 2009 to 2011, each subsystem presented unsteady variation, and the collaboration factors within industries also changed unsteadily, all of which resulted in ups and downs. As a consequence, the overall collaboration degree of the enterprise grew slowly. After the end of 2011, the overall collaboration degree of the enterprise failed to reach the previous levels, and the costs saved in the internal transactions of industries dropped significantly. Consequently, the collaboration degree within industries decreased, which exerted significant influence on the overall collaboration degree of the enterprise; the overall collaboration degree had difficulty in bouncing back to its previous level.

In 2014, the collaboration degree within coal-electric industries exhibited a significant increase, which had a large influence on the overall collaboration degree; it promoted the increase in the overall collaboration degree of the enterprise. However, in 2014, the coal-electric integration experienced rapid development, and the various collaborative factors among industries all showed a rising tendency. At the same time, the costs saved in the internal transactions increased, accompanied by an overall enhanced degree of collaboration of the enterprise.

\section{Policy Suggestions}

In order to sufficiently verify the collaboration degrees between the coal industry and the electric power, chemical, and equipment industries, the average order degrees of the three subsystems in the period of 2007 to 2014 were calculated as $0.3961,0.3514$, and 0.4741, respectively. By comparing the three data points, the collaboration degree of the coal-equipment industry is shown as the highest, followed by the coalelectric industry, and the coal-chemical industry as the lowest degree of collaboration.

Through data analysis, we discovered that the collaboration degree was mainly related to the value of the internal transactions of the industries. The total expenditures of the internal transactions of the coal-equipment, coal-electric, and coal-chemical industries were 961,536 yuan, 313,521 yuan, and 246,684 yuan, respectively. Therefore, the collaboration degree presents a positive correlation with the total expenditure of internal transactions of the industries. Thus, the expenditures on transactions affect the collaborative development of the subsystems to some extent. Moreover, the collaboration degree is also related to the degree of the joint development between industries and the collaboration of intangible assets, among others. The weights of the aforementioned influential indices in the coal-equipment industry are obviously higher than those in other industries, leading to the fact that the order degree of the coal-equipment industry is significantly higher than that of other subsystems.

Therefore, merely from the perspective of industrial collaboration, this research suggests that this enterprise should vigorously develop the existing coal-equipment industry and carry out further expansion based on existing development advantages. At the same time, to improve the collaborative relationship in the coal-electric and coal-chemical industries, factors such as market, management, and scale should be taken into account. By doing so, the joint development between industries is expected to be enhanced to achieve the coordinated development of the coal-equipment industry 
and thus improve the overall collaboration degree of the enterprise.

At the same time, during the diversified development of enterprises, the scale consistency, management collaboration, and market cooperation between industries need to be fully considered to ensure that each industry can achieve favorable collaborative development in various fields. Favorable collaborative development will not appear in the overall mechanism of the enterprise unless the relationships among various fields are well coordinated. Simultaneously, the enterprise should consult, simulate, and assimilate the advantageous collaborative factors of other industries, to carry out secondary innovation. Notably, collaboration factors between industries have to be adjusted continuously to be effective for industrial development.

\section{Competing Interests}

The authors declare that there is no conflict of interests regarding the publication of this paper.

\section{Acknowledgments}

The authors are grateful for the financial support received from the National Natural Science Foundation of China (no. 71403267), the Fundamental Research Funds for the Central Universities (2014XT06), and Innovation Engineering Project of Postgraduate Education in Jiangsu Province (KYZZ15_0372).

\section{References}

[1] C. M. Li, R. Nie, and D. Wang, "Scientific mining in Chinaproblems, progress, and prospects," Electronic Journal of Geotechnical Engineering, vol. 20, no. 15, pp. 6491-6506, 2015.

[2] M. Song and J. Wang, "Coal price fluctuations in China: economic effects and policy implications," Journal of Renewable and Sustainable Energy, vol. 8, no. 6, Article ID 065901, 2016.

[3] H. I. Ansoff, Corporate Strategy: An Analytic Approach to Business Policy for Growth and Expansion, McGraw-Hill, New York, NY, USA, 1965.

[4] H. I. Ansoff, The New Corporate Strategy, Wiley, New York, NY, USA, 1988.

[5] H. Haken, "Introduction to synergetics," in Synergetics: Cooperative Phenomena in Multi-Component Systems, Springer, 1973.

[6] H. Haken, Advanced Synergetics, Springer, Berlin, Germany, 1983.

[7] D. Hu, "The connection of enterprise clusters competitive advantages with industry interrelation and synergy," Chinese Journal of Management, vol. 6, article 14, 2006 (Chinese).

[8] E. K. Clemons and M. C. Row, "Information technology and industrial cooperation: the changing economics of coordination and ownership," Journal of Management Information Systems, vol. 9, no. 2, pp. 9-28, 1992.

[9] P. C. Ensign, "Interrelationships and horizontal strategy to achieve synergy and competitive advantage in the diversified firm," Management Decision, vol. 36, no. 10, pp. 657-668, 1998.

[10] S. X. Li and R. Greenwood, "The effect of within-industry diversification on firm performance: synergy creation, multi-market contact and market structuration," Strategic Management Journal, vol. 25, no. 12, pp. 1131-1153, 2004.
[11] T. Sueyoshi, M. Goto, and J. Shang, "Core business concentration vs. corporate diversification in the US electric utility industry: synergy and deregulation effects," Energy Policy, vol. 37, no. 11, pp. 4583-4594, 2009.

[12] R. F. Bruner, "Does M\&A pay? A survey of evidence for the decision maker," Journal of Applied Finance Theory, Practice and Education, vol. 12, no. 1, pp. 48-88, 2002.

[13] T. K. Mukherjee, H. Kiymaz, and K. Baker, "Merger motives and target valuation: a survey of evidence from CFOs," Journal of Applied Finance, vol. 14, no. 2, pp. 7-24, 2004.

[14] B. Villalonga, "Diversification discount or premium? New evidence from the business tracking series," Journal of Finance, vol. 42, no. 2, pp. 943-963, 2004.

[15] A. Zaheer, X. Castañer, and D. Souder, "Synergy sources, target autonomy, and integration in acquisitions," Journal of Management, vol. 39, no. 3, pp. 604-632, 2013.

[16] S. Garzella and R. Fiorentino, "A synergy measurement model to support the pre-deal decision making in mergers and acquisitions," Management Decision, vol. 52, no. 6, pp. 1194-1216, 2014.

[17] H. Haken, "Synergetics," Physics Bulletin, vol. 28, no. 9, pp. 412414, 1977.

[18] Q. S. Meng and W. X. He, "Study of the coordinating measurement model with respect to composite system," Journal of Tian Jin University, vol. 33, no. 4, pp. 444-446, 2000 (Chinese).

[19] T. L. Saaty, "What is the analytic hierarchy process?" in Mathematical Models for Decision Support, pp. 109-121, Springer, Berlin, Germany, 1988.

[20] N. Khalil, S. N. Kamaruzzaman, and M. R. Baharum, "Ranking the indicators of building performance and the users' risk via Analytical Hierarchy Process (AHP): case of Malaysia," Ecological Indicators, vol. 71, pp. 567-576, 2016.

[21] G. Raviv, A. Shapira, and B. Fishbain, "AHP-based analysis of the risk potential of safety incidents: case study of cranes in the construction industry," Safety Science, vol. 91, pp. 298-309, 2017. 


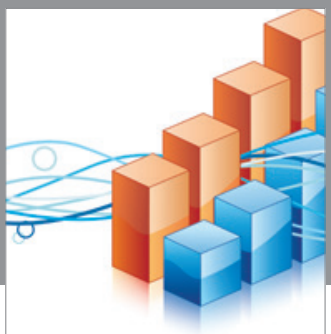

Advances in

Operations Research

vatem alat4

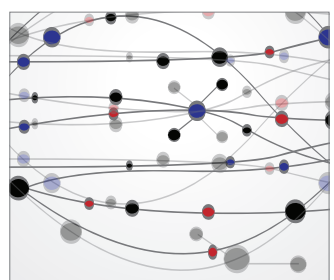

\section{The Scientific} World Journal
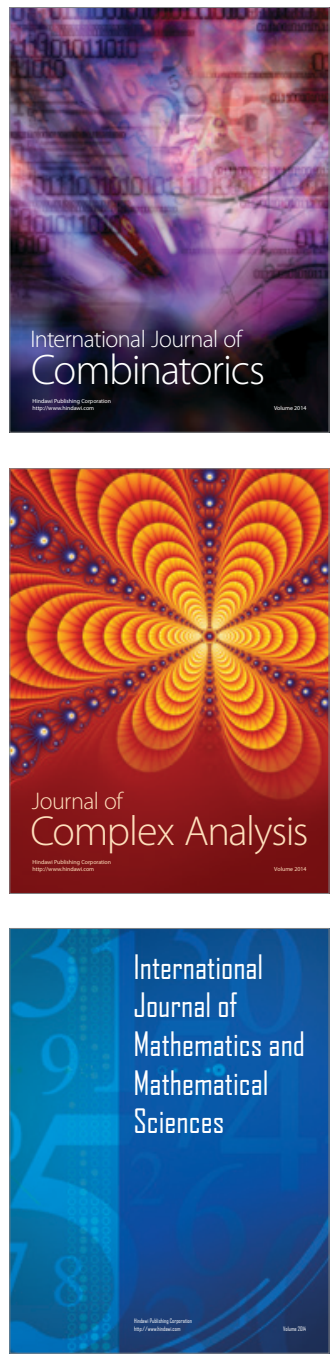
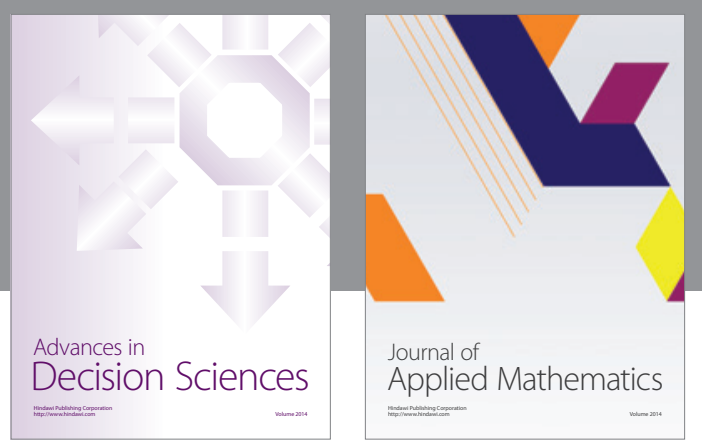

Algebra

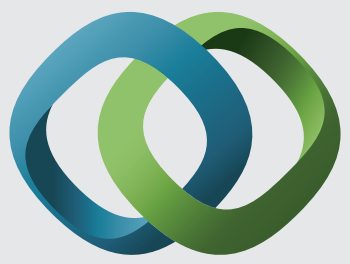

\section{Hindawi}

Submit your manuscripts at

https://www.hindawi.com
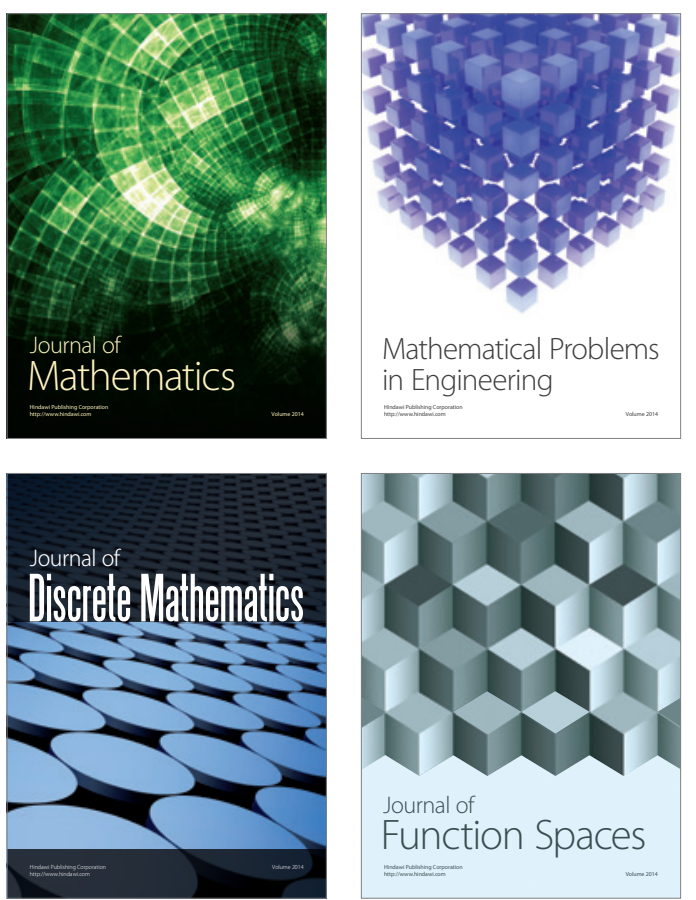

Mathematical Problems in Engineering
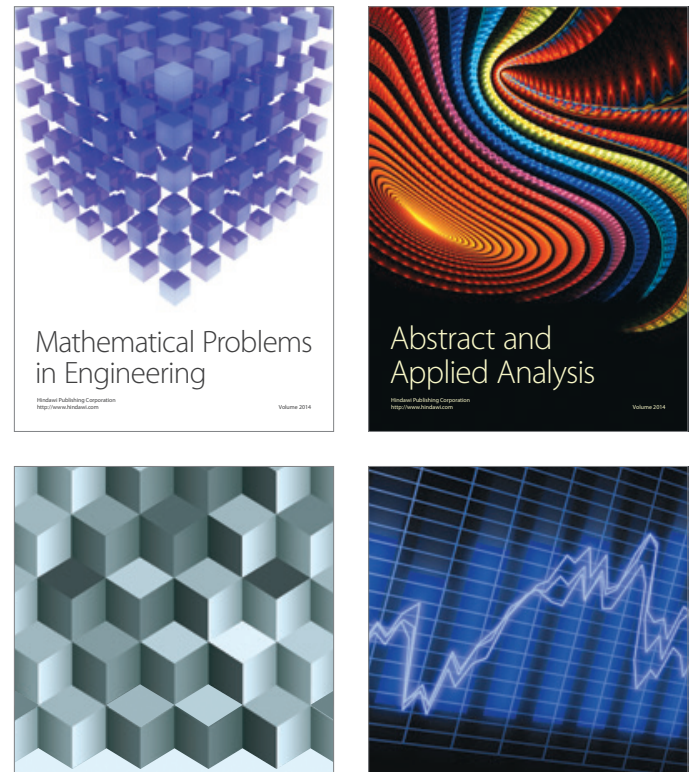

Journal of

Function Spaces

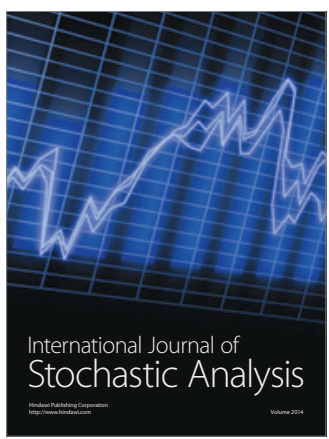

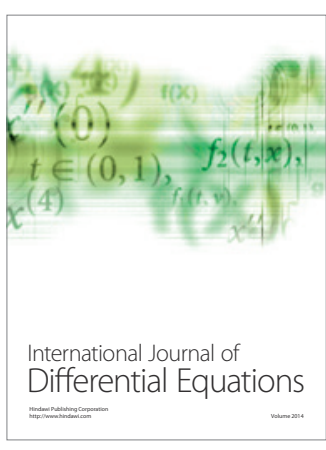
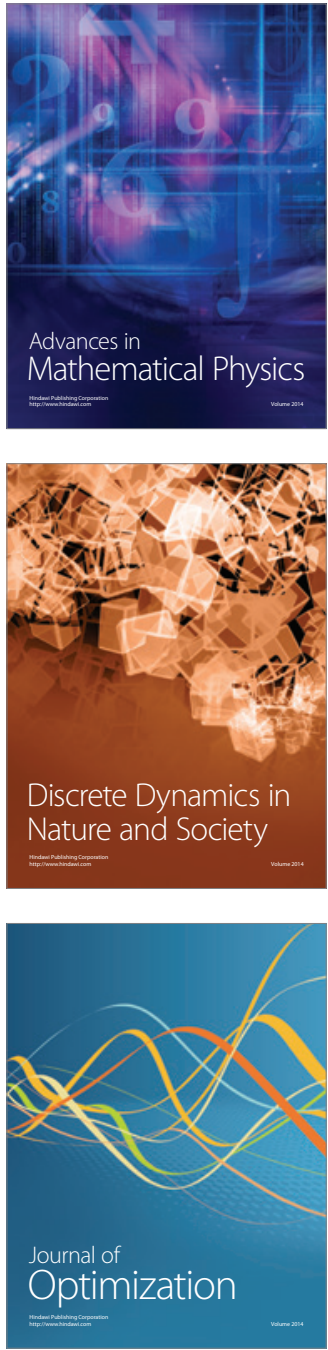